\section{LIPOID PNEUMONIA}

BY

\section{S. A. PROPERT, M.A., M.R.C.P.}

Senior Physician at the Essex County Hospital, Colchester

For some years it has been recognized that intranasal medication with oily preparations may lead to changes in the lungs. Because of its blandness oil gravitates from the nasopharynx to the larynx, and may enter the lungs without eliciting a cough reflex. In 1925 Laughlen first called attention to a condition which has since been reported from time to time under such names as oilaspiration pneumonia, lipoid-cell pneumonia, oil pneumonia, and stéatose pulmonaire. The changes induced in the lungs by the presence of oil may occur apart from nasal medication. Many of the reported cases have been in infants or small children, and it appears that in weakly infants small quantities of milk foods, cod-liver oil, or laxative doses of paraffin may be aspirated and give rise to the condition. The fact that such substances are often administered to a debilitated child when it is lying on its back increases the chances of aspiration; so also does a mechanical defect of the palate or a nervous disease affecting deglutition.

It has been shown experimentally by Cannon and Walsh (1938) that medicated nasal oils and even plain light mineral oil are definitely toxic to pulmonary tissues, causing the characteristic picture of acute lipoid pneumonia. The alveoli of the lungs become "oil-logged," oedema occurs, and phagocytic cells migrate into the alveoli, where they engulf globules of oil. Usually there is no secondary infection, but this may arise should the oil be infected with virulent bacteria on its passage to the lungs. The relative toxicity of various oils has been investigated experimentally on laboratory animals (Pinkerton, 1927). Animal oils, such as cod-liver oil, chaulmoogra oil, and cream, are highly irritating, while pure vegetable oils are considerably less so.

The case of lipoid pneumonia recorded below caused some difficulty in diagnosis because the patient did not at first mention that he had been in the habit of douching his nasopharynx with liquid paraffin. From the first, however, anomalous features in the history and physical findings gave reason to believe that the patient was not suffering from any usual form of pneumonitis. When, after direct questioning, he admitted that he had used large quantities of paraffin for the treatment of nasal catarrh it became evident that he was suffering from this peculiar type of pneumonia, and it was possible by subsequent investigations to confirm the diagnosis.

\section{Case History}

A male caretaker aged 54 was admitted to hospital on June 3,1940 , with a provisional diagnosis of pneumonia. He stated that his health had been normal until 1923, when he started work as a caretaker in a feather-curling factory. At this time he developed nasal catarrh, for which he was advised to use a nasal douche of salt water and thymol, and then to instil into his nose a small quantity of paraffin. His symptoms were but slightly relieved. In 1935 he attended hospital for examination, and nasal polypi were removed. After operation he continued the use of nasal douches followed by liquid paraffin. In his own words, he "flooded the nose frequently," using as much as $3 \mathrm{oz}$. daily.

In 1937 he began to suffer from attacks of breathlessness and bronchial catarrh. Attacks were usually apyrexial; on some occasions they were preceded by shivering, sweating, and general malaise, and were accompanied by an irregular temperature not higher than $100^{\circ} \mathrm{F}$. During the attacks, which occurred at intervals of two or three weeks, he felt great tightness in the chest, had a " rattling " cough, and was so breathless that he was unable to move from his bed for several days. Towards the end of attacks he would expectorate white "jelly-like" sputum. Between attacks he was able to work, though he became dyspnoeic on exertion and had a chronic cough. When he was very breathless he noticed palpitations. His ankles had never become swollen.

Four days before admission to hospital breathing became extremely difficult; on this occasion he had not much cough. The doctor who examined him at his home found an impaired percussion note at the base of both lungs, with numerous moist sounds. Sulphapyridine (M \& B 693) was given in full doses for forty-eight hours without effect.

On admission his temperature was $99.4^{\circ} \mathrm{F}$., the pulse 104 and irregular, and the respiratory rate 35 . His state of nourishment was good. He was in acute distress on account of breathlessness, and was slightly cyanosed about the lips, nose, ears, and finger-tips. Labial herpes was present. The tongue was moist and furred. In spite of respiratory distress he did not have the gravely ill and toxic appearance of a pneumonia case. The neck veins were not engorged, nor were there any other signs of cardiac congestion. The chest movements were poor but equal on the two sides. The percussion note was impaired at the right base as high as the middle of the scapula and to a less extent at the left base. Coarse crepitations were audible over these areas. No tubular breathing or pleural friction sounds were heard. Vocal resonance was diminished at the right base. The heart was normal in size : its rate was 104 , and irregularity due to numerous extrasystoles was present; no murmurs were audible. The blood pressure was $130 / 80$. No abnormal constituents were present in the urine, and examination of other systems was negative.

Radiologically the chest appearance was consistent with a bronchopneumonia mostly affecting the bases. Shadows were particularly marked in the region of the hila. The sputum appeared to be mucoid, and in water small globules, of oil, in addition to the normal air bubbles, could be seen. Direct films of sputum showed globules of free oil to be present.

The sputum was examined by Dr. C. F. Barwell, whose report was: "Copious very tenacious sputum, mainly mucoid, with purulent streaks. The mucoid. fraction shows abundant lipophage cells and accumulations of extracellular oil globules, the larger visible microscopically. Pus cells with moderate numbers of Gram-positive cocci in pairs and short chains and Gram-negative diplococci are present in the purulent streaks, of which culture yields profuse Neisseria catarrhalis and scanty growth of a viridans streptococcus."

Progress.-After the patient's admission to hospital the pulse gradually became normal in rhythm. The temperature remained normal except for an occasional rise to $99^{\circ} \mathrm{F}$. Severe dyspnoea lasted for ten days; after this he was able to sit up in a chair, and only became breathless if he attempted to exert himself. Improvement in physical signs lagged behind subjective improvement, and an impaired percussion note is still present at both bases together with coarse rales. Radiologically there is some clearing of the earlier shadows, but only to a limited extent. The sputum still shows numerous lipophages. He now feels well. It appears that the phase of secondary infection is at an end but that oil is still present in the bases of the lungs, and this produces mechanically the existing physical signs.

\section{Comments}

The diagnosis of lipoid pneumonia has not infrequently been made at post-mortem examinations. Some of the reported cases of "giant-cell pneumonia" and "desquamative pneumonia "may possibly have been due to the aspiration of oils. In any unusual type of pneumonitis it is worth while excluding that possibility, which can usually be done simply enough by direct questioning. The use of nasal oil may not be mentioned spontaneously as it is often considered an irrelevant point.

In lipoid pneumonia radiographs of the chest are not pathognomonic, but the diagnosis may be confirmed by the examination of the sputum and the finding of free oil globules or lipophages. In cases which are complicated 
by secondary infection and thus have a bacterial bronchitis or pneumonia the usual treatment for these conditions should be applied.

REFERENCES

Cannon, P. R.. and Walsh, T. E. (1938). Int. Clin. n.s. 1, 3. 109

Pinkerton, Henry (1927). Amer, J Dis. Child. 33. 259.

\section{COMPARISON OF THE TOXICITY OF TRYPARSAMIDE AND NEOCRYL IN THE TREATMENT OF NEUROSYPHILIS}

\author{
BY
}

A. O. F. ROSS, M.D., D.P.H.

Senior Clinical Venereal Diseases Officer, City and Port of Liverpool; Lecturer in Specific Diseases, University of Liverpool

A preliminary account of neocryl (sodium succinanilomethylamide- $p$-arsonate), together with some clinical and laboratory evidence of its effect on syphilis in all stages of the disease, was published by Yorke and others in 1936. While it was never intended that neocryl should be used in the earlier stages, evidence was produced that its spirochaeticidal effect was greater than that of tryparsamide when infectious lesions were treated by these drugs alone.

\section{Glyn-Hughes's Conclusions}

Glyn-Hughes (unpublished) studied the effects of these pentavalent arsenicals in cases of neurosyphilis. His study embraced 77 cases (11 G.P.I., 15 taboparesis, 25 tabes, 26 neurosyphilis), and in those treated solely by pentavalent arsenicals-59 in all-his conclusions were as under:

G.P.I. -4 cases were treated with tryparsamide and 7 with neocryl. All but one deteriorated and later required asylum treatment. One patient treated with neocryl showed improvement. It is concluded that the influence of tryparsamide and of neocryl in general paralysis with pronounced mental symptoms is very small.

Taboparesis. -5 cases were treated with tryparsamide: 1 patient was unaffected and died; 2 showed definite improvement, but 1 died later; 2 showed slight improvement, but 1 who had some degree of optic atrophy at the beginning of treatment became blind and died. 6 cases were treated with neocryl: 5 showed definite improvement, but 1 defaulted and relapsed later; the remaining patient had pronounced mental symptoms and, although he received much treatment, deteriorated and was admitted to an asylum. It is concluded that neocryl is superior to tryparsamide in taboparesis though not universally successful.

Tabes. -12 cases were treated with tryparsamide: 4 showed marked improvement ; 3 were slightly improved; the remaining 5 patients were either unaffected or became worse and died. 13 cases were treated with neocryl, 2 of these being in the advanced stage: 11 cases were definitely improved (in fact, 5 of these patients were able to resume their work, which they had been compelled to give up owing to their condition): 2 advanced cases, mentioned above, deteriorated, and these patients died.

Early Neurosyphilis. - 4 cases were treated with tryparsamide: 1 improved greatly and 2 others to some extent. 8 cases were treated with neocryl: 7 improved considerably and 1 improved to some extent but defaulted later.

In tabes and early neurosyphilis, therefore, treatment with neocryl was more successful than with tryparsamide, although both drugs were of much value.

Glyn-Hughes also mentions that 90 cases had been treated with neocryl without any damage to the optic nerve; and, indeed, optic atrophy previously present did not progress, whereas tryparsamide seriously damaged the eyes of 11 patients out of a total of 46 , actual blindness supervening in some of these.

\section{The Present Investigation}

Our series consists of over 570 cases treated between 1936 and July, 1939, with either tryparsamide or neocryl, or occasionally with both at different times. Included in it are a number of cases suffering from interstitial keratitis and of late cases in which a suspicion of neurosyphilis, without serological evidence, existed. The standard dose of each drug was 3 grammes intravenously once weekly until 30 grammes had been administered; but in a few cases, owing to age, infirmity, or other condition calling for caution, smaller doses were given. Approximately $8.5 \mathrm{~kg}$. of each drug was employed in the treatment of the cases under review. It should be noted that neocryl is rather less soluble than tryparsamide, but 3 grammes can easily be dissolved in $20 \mathrm{c.cm}$. of distilled water.

A recent survey of the records of this series of cases, made at least twelve months after the end of treatment, has confirmed the early impression that the therapeutic results obtained with neocryl are in no way inferior to those obtained with tryparsamide. In view of this fact it seemed of importance to make an analysis of the toxic manifestations of the two compounds. The cases were unselected, but it must be remembered that early optic atrophy has always been considered an absolute contraindication to tryparsamide therapy unless the neurological condition of the patient necessitated risks being taken. As the work progressed and it became gradually realized that neocryl was relatively harmless, this compound was chosen for cases exhibiting visual disturbance, and eventually a state of affairs was reached when neocryl was given without hesitation to all cases, even when there was evidence of optic atrophy.

TABLE I.-Summarizing the Toxic Manifestations observed in 256 Cases treated with Tryparsamide

\begin{tabular}{|c|c|c|c|c|c|c|c|c|c|c|c|}
\hline \multirow[b]{2}{*}{ Type } & \multirow[b]{2}{*}{ 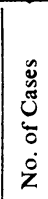 } & \multirow{2}{*}{ 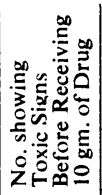 } & \multirow[b]{2}{*}{ 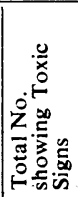 } & \multirow[b]{2}{*}{ 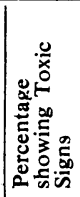 } & \multicolumn{7}{|c|}{ Toxic Reactions } \\
\hline & & & & & 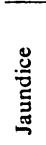 & 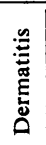 & 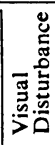 & 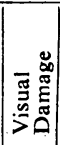 & 莣 & 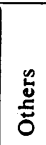 & . \\
\hline $\begin{array}{l}\text { G.P.I. } \quad \ldots \\
\text { Tabes } \\
\text { Taboparesis } \\
\text { Neurosyphilis } \\
\text { Late syphilis }\end{array}$ & $\begin{array}{r}30 \\
115 \\
11 \\
45 \\
55\end{array}$ & $\begin{array}{r}2 \\
23 \\
1 \\
6 \\
4\end{array}$ & $\begin{array}{r}3 \\
49 \\
2 \\
17 \\
7\end{array}$ & $\begin{array}{l}10 \\
43 \\
18 \\
38 \\
13\end{array}$ & $\begin{array}{r}1 \\
10 \\
1 \\
4 \\
2\end{array}$ & $\begin{array}{l}0 \\
8 * \\
0 \\
4 \\
0\end{array}$ & $\begin{array}{r}1 \\
23 \\
0 \\
10 \\
2\end{array}$ & $\begin{array}{l}1 \\
4 \dagger \\
1 \dagger \\
4 \\
1 \dagger\end{array}$ & $\begin{array}{l}0 \\
4 \\
0 \\
0 \\
2\end{array}$ & $\begin{array}{l}\mathbf{0} \\
\mathbf{5} \\
\mathbf{0} \\
\mathbf{0} \\
\mathbf{0}\end{array}$ & $\begin{array}{r}3 \\
54 \\
2 \\
22 \\
7\end{array}$ \\
\hline Totals .. & 256 & 36 & 78 & 30 & 18 & 12 & 36 & 11 & 6 & 5 & 88 \\
\hline
\end{tabular}

*One developed purpura.

tOne became blind.

N.B. -47 out of the 88 reactions affected vision

TABLE II.-Summarizing the Toxic Manifestations observed in 314 Cases treated with Neocryl

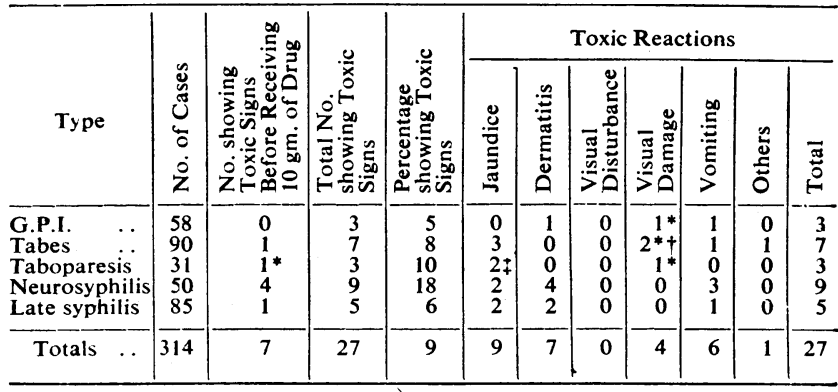

* Onz had optic atrophy before treatment and the visual condition deteriorated 9 other cases with optic atrophy were treated without ill effect.

† One suddenly became blind.

$\ddagger$ One died of toxic jaundice. 